\title{
EVALUATION OF DELAYED SPLIT EXPANSION TECHNIQUE FOR HORIZONTAL AUGMENTATION OF NARROW MANDIBULAR ALVEOLAR RIDGE FOR IMPLANT PLACEMENT WITHOUT GUIDED BONE REGENERATION
}

Sally Elsayed Abdelsameaa*, Eman Abdel Salam Yousef* and Noha Ahmed Mansour*

\begin{abstract}
Objective: To evaluate the effect of application of delayed split expansion technique without guided bone regeneration for implant placement in narrow posterior mandibular ridge.

Patients and methods: Fourteen patients with narrow posterior mandibular ridge were included in this prospective study. All patients treated by a delayed expansion technique with implant placement, receiving a total of thirty implants. All patients were evaluated clinically and radiographically by multi-slice CT scan. The width of the alveolar ridge was measured before implantation, immediately after implantation, and after 6 months. Marginal bone loss was calculated buccally and lingually as the difference between bone height measurements immediately post-implant insertion and after 6 months.
\end{abstract}

Results: The average increase of the alveolar ridge width was $4.22 \pm 0.94 \mathrm{~mm}$ after 6 months, which showed a high statistically significant value $(\mathrm{P} \leq 0.001)$. The mean values of buccal and lingual marginal bone loss were $0.403 \pm 0.26$ and $0.217 \pm 0.20 \mathrm{~mm}$ respectively, which showed statistically non-significant values $(\mathrm{P}=0.087$ and $\mathrm{P}=0.092$ respectively).

Conclusion: The use of delayed expansion technique without guided bone regeneration is a simple efficient technique for horizontal augmentation of the narrow posterior mandibular ridge for implant placement. It offers less incidence of complications, less morbidity, and less cost than other augmentation techniques. It represents a modification of the conventional technique and is especially interesting for those patients with highly compact bone and initial insufficient bone ridge width for implant placement.

KEYWORDS: Dental implant, delayed expansion, horizontal augmentation, piezo-surgery

* Lecturer of Oral Surgery, Department of Oral \& Maxillofacial Surgery, Faculty of Dentistry, Mansoura University, Mansoura, Egypt. 


\section{INTRODUCTION}

Deficiency of the width of the alveolar ridge can jeopardize insertion of the dental implants. Therefore, reconstruction of the narrow alveolar ridge is mandatory from the biomechanical point of view. Various surgical techniques including guided tissue regeneration, bone blocks, ridge splitting techniques and distraction osteogenesis have been introduced for reconstruction of narrow ridges. ${ }^{1-3}$ The alveolar ridge splitting technique is considered as one of the most successful augmentation techniques that has reported significant success rates and good outcomes on the long-term. ${ }^{4}$

Tatum is the pioneer of introducing ridge splitting technique for root form implants. ${ }^{5}$ This technique is suitable for horizontal deficiencies in cases of 3 to $6 \mathrm{~mm}$ bucco-lingual bone thickness with at least 1 $\mathrm{mm}$ of cancellous bone between the two cortical plates. This guarantees $1.5 \mathrm{~mm}$ thickness of cortical and cancellous bone on both sides of the split ridge which allows bone expansion, proper blood supply and good instrumentation. ${ }^{1}$

The alveolar ridge splitting involves a longitudinal osteotomy using hand instruments, microsaws, piezosurgery or an ultrasonic device for induction of a controlled greenstick fracture between the cortical plates. ${ }^{6-9}$ The buccal cortical plate can be laterally positioned by osteotomes, screw spreaders or horizontal spreaders and chisels. This space is spontaneously filled with newly formed bone as in the healing process of an extraction socket. ${ }^{10}$ This technique enables immediate or late dental implants installation, with or without the use of biomaterials, which improve regeneration between fractured cortices, working as a framework. ${ }^{11}$

The crest split technique is privileged with many advantages over other traditional augmentation techniques; the space created by expansion heals similar to the healing process of an extraction socket. It enables immediate implant placement and eliminates the need for bone harvesting reducing time and morbidity. ${ }^{12}$ In spite of being more appropriate for maxillary ridge, the crest split technique can be also performed in posterior mandibular region as long as the satisfactory conditions exist. ${ }^{13}$

On the other hand, uncontrolled fracture or avascular necrosis may result from split technique, especially in areas with thick cortical plates and less flexibility such as posterior mandible. ${ }^{14}$ One of the reported major surgical complications after ridge splitting is the buccal cortical plate fracture. ${ }^{1,15}$ Therefore, a staged split ridge expansion was introduced to preclude mal-fracture of the osteotomized mandibular buccal plate. The staged split expansion technique consists of expanding the bone in two consecutive stages. ${ }^{16}$ It precludes the harvesting of autogenous bone and the need of fixing a block with screws. Additionally, the incidence of uncontrolled fracture as well as the avascular necrosis could be minimized. ${ }^{4}$

This study was done to evaluate the delayed expansion technique for augmentation of the alveolar ridge with implant placement in the posterior region of the mandible without adding bone grafts.

\section{PATIENTS AND METHODS}

This study was performed on fourteen patients with a long span, partially edentulous narrow posterior mandibular ridges who attended the outpatient clinic, Oral Surgery Department, Faculty of Dentistry, Mansoura University.

The study followed the Declaration of Helsinki on medical protocol and ethics and was approved by the Ethical Review Board of Mansoura University. All patients were informed about the risks and benefits of the procedure and they provided written informed consents for the treatment plan.

\section{Patients' selection: ${ }^{17}$}

This study included patients with adequate bone height in the edentulous posterior mandibular region (at least $10 \mathrm{~mm}$ ), but narrow buccolingual 
ridge dimension ranging from 3 to $5 \mathrm{~mm}$ that was not sufficient for placement of conventional dental implants of desirable width and in a correct angulation.

Patients suffering any systemic contraindications to surgery such as severe renal or liver disease, bleeding and clotting disorders, and uncontrolled diabetes, history of radiation in head and neck region, active chemotherapy, deficient bone height (only ASA classes I and II were included), smoking more than 15 cigarettes/day ${ }^{17}$ and active periodontal disease of the adjacent tooth were excluded.

\section{Pre-operative phase:}

The assessment of the ridge was done with the help of clinical intraoral examination, and radiographic examination using multi-slice computed tomography (MSCT) scans*.

(The CT for the patients are refereed in the "MEASUREMENT OF THE OUTCOMES" section AS FIGURE 2)

\section{Surgical phase: ${ }^{17}$}

First stage: Before surgical intervention, rinsing with anti-septic mouthwash rinse** was performed, also lips and perioral area were swaped with chlorhexidine. The surgical field was anesthetized using Mepivacaine Hydrochloride 2\% and Levonordefrin 1: 20,000***. A full-thickness mucoperiosteal flap was elevated to expose mandibular alveolar ridge. The crestal incision was done rather lingually so as to compensate for the increase in ridge width subsequent to the ridge splitting. The lingual flap was minimally reflected in order to maintain proper blood supply to the bone.

\section{(Figure 1A)}

Afterwards, a piezo-surgery device**** was used for a crestal osteotomy which started $2 \mathrm{~mm}$ away from the adjacent tooth.

According to the number of implants and the space between the implants planned to be placed, the extension of the horizontal osteotomy was determined. Thereafter, two vertical osteotomies of about two thirds the length of the proposed dental implants were performed at the mesially and distally to the horizontal osteotomy. The vertical cuts completely transected the buccal cortical plate into the marrow space without any expansion of the cortical plates. (Figure 1B) Then, the mucoperiosteal flap was approximated allowing the region of the corticotomies to heal (for development of soft callus) for 4 weeks. Neither buccal bone displacement nor expansion was performed in this stage, to allow healing process between the splitted bone, similar to that occurring in the extraction sockets. ${ }^{4}$ (Figure 1C)

Second stage: A crestal incision was done exposing only the alveolar crest without any extension to the buccal wall, and the amount of the formed bone was noticed. Minimum reflection of the buccal flap was done for maintaining the blood supply to the buccal cortical plate. Using a small chisel, the segmented bone was carefully separated and mobilized so as to provoke a greenstick fracture.

Screw type expanders***** were used to achieve lateral expansion. Thereafter, expanders of progressive sizes were introduced to increase the gap between the cortices to achieve the desired amount of horizontal ridge expansion. (Figure 1D)

* Low-dose multi-slice computed tomography scans. (slice thickness $=1.25 \mathrm{~mm}$; interval $=0.6 \mathrm{~mm}$; table feed $=11.25 \mathrm{~mm} \times$ rotation; field of view $=0.6 \mathrm{~mm}$; matrix $=512 \times 512 / 200 \mathrm{~mA} / 80 \mathrm{kV})$. The scanned images were studied by two examiners using Adobe Photoshop Software (Adobe Systems Inc., San Jose, CA, USA).

** Hexitol Chlorhexidine $\mathrm{HCl} 1.25 \%$, by Hexitol ${ }^{\circledR}$ mouthwash: Arab Drug Company (ADCO), Cairo, Egypt).

*** Scandonest; Septodont, France.

**** Piezotome Cube, Acteon.

***** Dio, Korea 


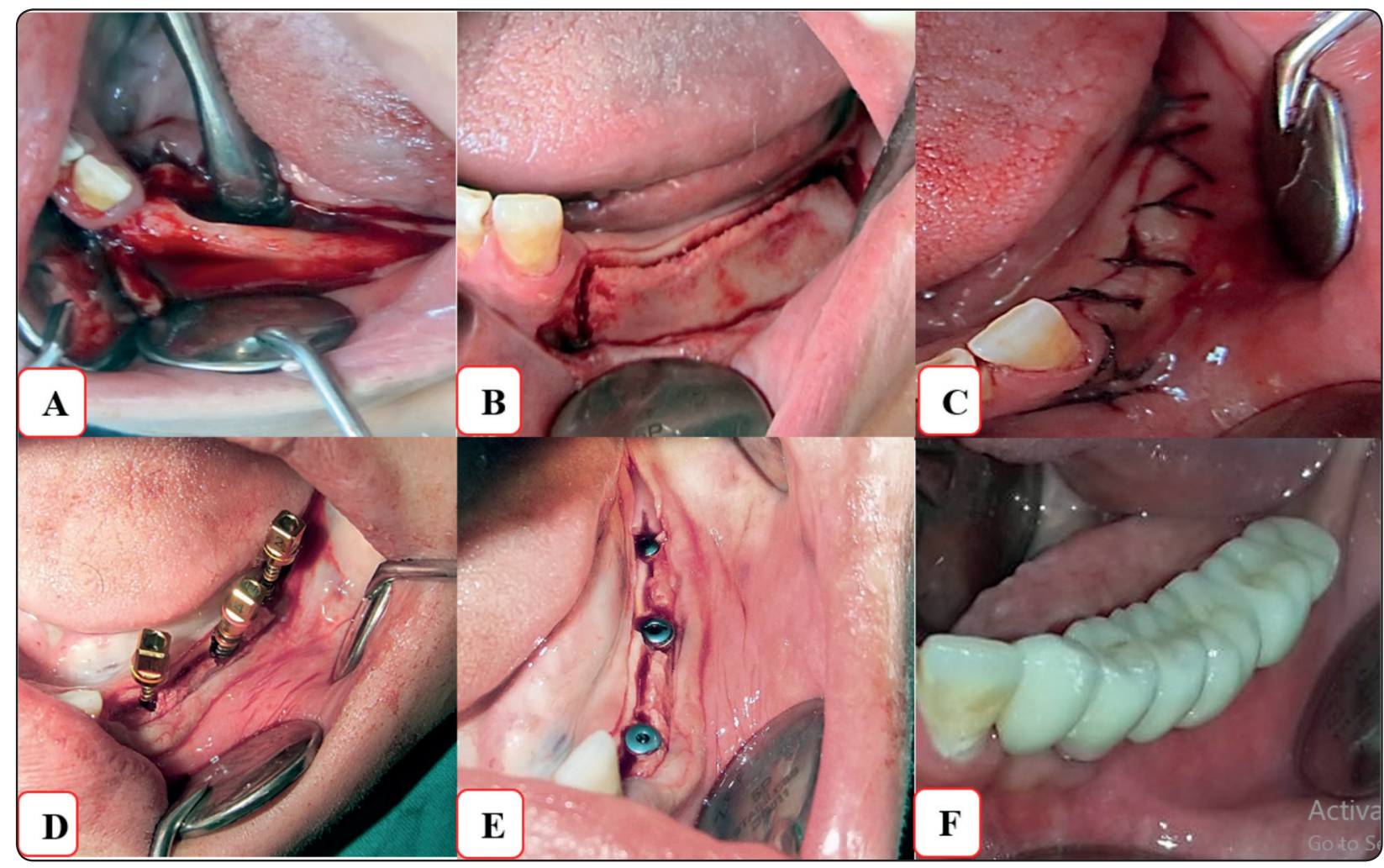

Fig. (1) A) Elevation of three-line pyramidal mucoperiosteal flap to expose the buccal aspect of the knife ridge. B) One crestal and 2 vertical corticotomies of the ridge. C) Re-approximation of the pyramidal mucoperiosteal flap and the area of corticotomies was left to heal. D) Expansion of the split ridge using expanders with increasing diameter until reaching the desired diameter. E) Placement of three implants in the osteotomy with the shoulder flushed with the level of bone. F) Placement of fixed ceramic prostheses.

The implant sites were prepared by using twist drills and the implants* were inserted in the osteotomy sites considering their shoulder to be flushed with the level of bone crest. (Figure 1E) According to the measured bone width and height on MSCT, the implant sizes were determined. For all cases, simple interrupted suturing with 3-0 braided black non-resorbable silk sutures was performed to achieve tension-free soft tissue closure.

\section{Post-surgical phase:}

Postoperative care included cold compresses over the lower lip applied for 20 min every hour for $6 \mathrm{~h}$ postoperatively. The patient was kept on a clear fluid diet for the first 24 hours, then a soft diet was maintained for the following day. Patients were advised to rinse the mouth with chlorhexidine gluconate $0.2 \%$ solution $2-3$ times a day for a week.

Patients were instructed to take antibiotic Amoxicillin with Clavulanate potassium** $1 \mathrm{mg}$ twice daily for 5 days and chymotrypsin*** $0.375 \mathrm{mg} 3$ times daily for 7 days. Diclofenac sodium $* * * *$ was prescribed once daily for pain relief when needed. Sutures were removed 10-14 days postoperatively.

\footnotetext{
*Two pieces root form endosseous implant. SM Hex implant system. Dio. Korea.

**Augmentin ${ }^{\circledR} 1 \mathrm{~g}$ Tablet by Galaxosmithkline co ltd, USA.

***Alphintern, Amoun Pharmaceutical Co Egypt S.A.E.

**** Olfen 100 SR. Medical Union Pharmaceuticals Co. (MUP) - Egypt. Under Licence from: Mepha Ltd. - Switzerland.
} 
After four months of the surgical procedure, the healing abutments were placed for two weeks, then removed, and a closed tray impression was made using silicon impression material (putty and light body) with implant analogues/implant copings in position. The final prosthesis was prepared and cemented on the abutment after establishing proper occlusion. (Figure 1F)

\section{Measurement of the outcomes:}

Using MSCT and the software mentioned before, both ridge width and height were measured in millimeters as follows:
A. Ridge width was measured $2 \mathrm{~mm}$ under crest pre-operatively (T0) (Figure 2A), immediately after implant screw placement (T1) (Figure 2B) and after 6 months (T2) to calculate the gain in ridge width (Figure $2 \mathrm{C}$ ).

B. Marginal bone height was measured on the buccal and lingual aspects of the implant immediately after its insertion (Figure 3A) (B0 and L0 respectively), and after 6 months of implant insertion (B1 and $\mathrm{L} 1$ respectively), to assess the amount of crestal bone loss. (Figure 3B)

The marginal bone loss was calculated using the implant as a reference by adjusting the crosssectional view in its center and bisecting it (showing

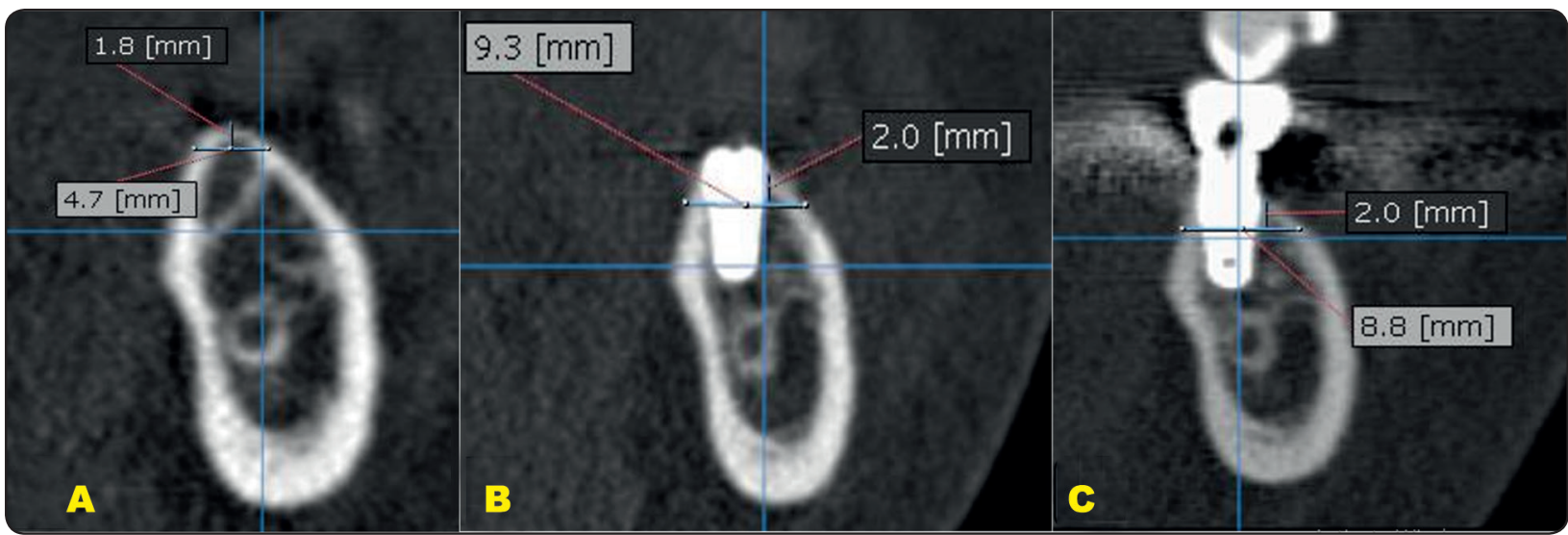

Fig. (2) Cross-sectional computed tomography scan showing changes in bone ridge width at implant site No 18: A) Initial bone width $\mathrm{T} 0=4.7 \mathrm{~mm}$. B) Post-split bone width $\mathrm{T} 1=9.3 \mathrm{~mm}$. C) Final bone width $\mathrm{T} 2=8.8 \mathrm{~mm}$.

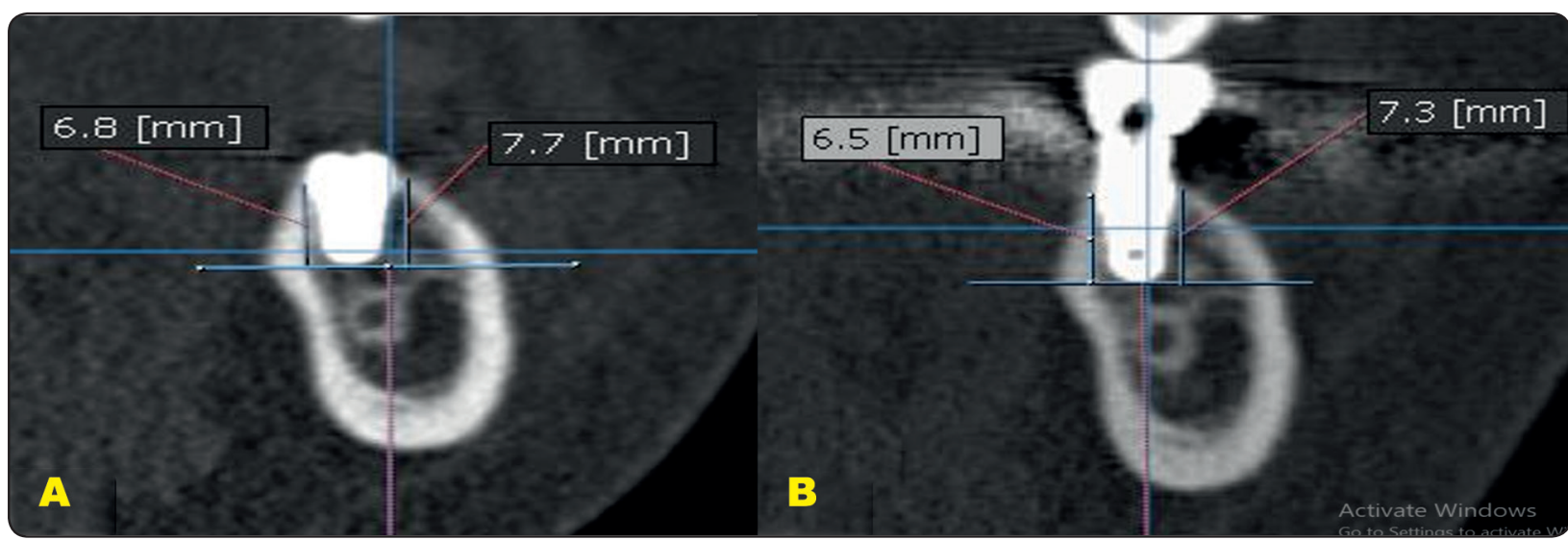

Fig. (3) Cross-sectional computed tomography scan showing buccal and lingual marginal bone loss: A) Post-split buccal bone height $\mathrm{B} 0=7.7 \mathrm{~mm}$ and post-split lingual bone height $\mathrm{L} 0=6.8 \mathrm{~mm}$. B) Final buccal bone height $\mathrm{B} 1=7.3 \mathrm{~mm}$ and final lingual bone height $\mathrm{L} 1=6.5 \mathrm{~mm}$ respectively. 
the buccolingual dimensions). Parallel to the implant, a line was drawn starting at the crest of the buccal plate of bone and ending at the apical level of the implant. This measurement was repeated for the lingual cortical plate.

\section{Statistical analysis}

Finally, the Statistical Package of Social Science (SPSS) program for Windows (Standard version 21) was used for analysis of the recorded data. The Shapiro test was first used to test the normality of data. Qualitative data were described in terms of number and percent.

Continuous variables were presented as mean \pm SD (standard deviation) for normally distributed data. The two paired groups were compared with paired $t$ test while more than two groups were compared with repeated measured ANOVA test. The threshold of significance is fixed at 5\% level for all of the statistical tests, considering the results significant only when $\mathrm{p} \leq 0.05$. The smaller the p-value obtained, the more significant are the results.

\section{RESULTS}

Thirty dental implants were inserted in 14 patients (4 males and 10 females) with a long span, partially edentulous narrow posterior mandibular ridges who attended the outpatient clinic, Oral Surgery Department, Faculty of Dentistry, Mansoura University. The age and sex distribution of patients as well as the specifications of the implants involved in this study are mentioned in Table $\mathbf{1}$.

The healing process was uneventful. None of the cases recorded dehiscence of the suture, wound infection or total fracture of the buccal plate. All patients had acceptable function of the implantsupported prostheses. Interestingly, no implant was lost during the whole study and all implants were osseointegrated .(Figure 4) and in function with mean survival rate of $100 \%$. Clinically, the intercortical bony gap seemed to be filled by newly formed bone
TABLE (1) Sociodemographic data and implant specifications size among studied group

\begin{tabular}{|c|c|}
\hline $\begin{array}{l}\text { Sociodemographic data and } \\
\text { implant specifications size }\end{array}$ & $\begin{array}{l}\text { Study group } \\
\qquad(\mathrm{n}=\mathbf{3 0})\end{array}$ \\
\hline Age (years) & \\
\hline Mean \pm SD & $34.37 \pm 7.72$ \\
\hline Min-Max & $19-47$ \\
\hline Gender & \\
\hline Male & $4(28.57 \%)$ \\
\hline Female & $10(71.43 \%)$ \\
\hline Implant specifications size (mm) & \\
\hline Diameter $($ Mean \pm SD $)$ & $4.17 \pm 0.26$ \\
\hline Length (Mean \pm SD) & $9.73 \pm 1.36$ \\
\hline
\end{tabular}

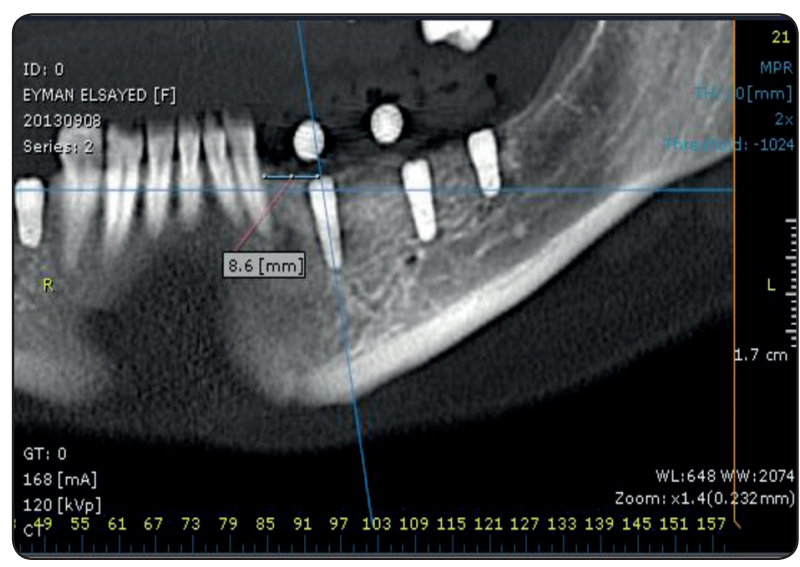

Fig. (4) Panoramic view showing successfully integrated dental implants.

\section{A. Ridge width}

The pre-operative ridge width values (T0) ranged from $3.2 \mathrm{~mm}$ to $4.8 \mathrm{~mm}$ with mean and standard deviation of $4.04 \pm 0.51$. Immediately after the split technique (T1), these values ranged from $6.8 \mathrm{~mm}$ to $10.8 \mathrm{~mm}$, with mean and standard deviation of $8.47 \pm 1.06$. After 6 months of implant insertion, ridge width values (T2) ranged from 6.6 $\mathrm{mm}$ to $10.6 \mathrm{~mm}$, with mean and standard deviation of $8.27 \pm 1.01$.

Referring to the pre-operative ridge width (T0), there was $4.22 \pm 0.94 \mathrm{~mm}$ mean gain of the healed 
augmented alveolar crest width after 6 months, which showed high statistically significant increase $(\mathrm{P}<0.001)$ when comparing T0 with T2. After 6 months, the values of the ridge width (T2) showed slight decrease than those measured immediately after the split technique (T1). This recorded statistically insignificant difference $(\mathrm{P}=0.109)$. (Table 2 and Figure 5).

\section{B. Marginal bone loss}

Regarding the mean buccal marginal bone loss, it was $0.403 \pm 0.26 \mathrm{~mm}$, and the mean lingual marginal bone loss was $\mathbf{0 . 2 1 7} \pm \mathbf{0 . 2 0} \mathbf{~ m m}$. The statistical analysis showed insignificant decrease in buccal and lingual bone heights at 6 months postoperatively when compared to the immediate postoperative bone heights $(\mathrm{P}=0.087, \mathrm{P}=0.092$ respectively). (Tables 3\& 4 and Figure 6).

TABLE (2): Showing changes in bone ridge width within the postoperative follow up period:

\begin{tabular}{|l|c|c|c|c|}
\hline \multirow{2}{*}{\multicolumn{2}{c|}{ Bone Ridge Width (mm) }} & \multicolumn{4}{|c|}{ Bone Ridge Width (mm) } \\
\cline { 2 - 5 } & T0 & T1 & T2 & Width Gain \\
\hline Mean \pm SD & $4.04 \pm 0.51$ & $8.47 \pm 1.06$ & $8.27 \pm 1.01$ & $4.22 \pm 0.94$ \\
Min-Max & $3.20-4.80$ & $6.80-10.80$ & $6.60-10.60$ & $2.20-5.90$ \\
\hline Repeated measured ANOVA test & \multicolumn{4}{|c|}{$\mathrm{F}=571, \mathrm{p} \leq 0.001 * *$} \\
\hline Paired t test & \multicolumn{3}{|c|}{$\mathrm{P} 1 \leq 0.001 * *, \mathrm{P} 2 \leq 0.001 * *, \mathrm{P} 3=0.109$} \\
\hline
\end{tabular}

T0= initial (presplit) buccolingual bone width

T2= final bone width (after 6 months)

P1: Comparison between TO and T1
$T 1=$ post-split (immediate postoperative) bone width

**highly significant $p \leq 0.001$

P2: Comparison between TO and T2

P3: Comparison between $T 1$ and T2

TABLE (3): Showing changes in buccal bone height within the postoperative follow up period

\begin{tabular}{|lc|c|c|}
\hline \multirow{2}{*}{ Buccal Bone Height } & \multicolumn{3}{c|}{ Buccal Bone Height } \\
\cline { 3 - 5 } & B0 & B1 & Crestal bone loss \\
\hline Mean \pm SD & $8.71 \pm 1.71$ & $8.54 \pm 1.83$ & $0.403 \pm 0.26$ \\
\hline Paired t test $\quad$ P value & \multicolumn{3}{|c|}{$\mathrm{t}=1.77, \mathrm{p}=0.087$} \\
\hline
\end{tabular}

B0= postoperative buccal bone height

B1= buccal bone height after 6 months

TABLE (4): Showing changes in lingual bone height within the postoperative follow up period

\begin{tabular}{|l|c|c|c|}
\hline \multirow{2}{*}{ Lingual Bone Height } & \multicolumn{3}{|c|}{ Lingual Bone Height } \\
\cline { 2 - 4 } & L0 & L1 & Crestal bone loss \\
\hline Mean \pm SD & $9.01 \pm 1.61$ & $8.92 \pm 1.75$ & $0.217 \pm 0.20$ \\
\hline Paired t test P value & \multicolumn{3}{|c|}{$\mathrm{t}=1.74, \mathrm{p}=0.092$} \\
\hline
\end{tabular}




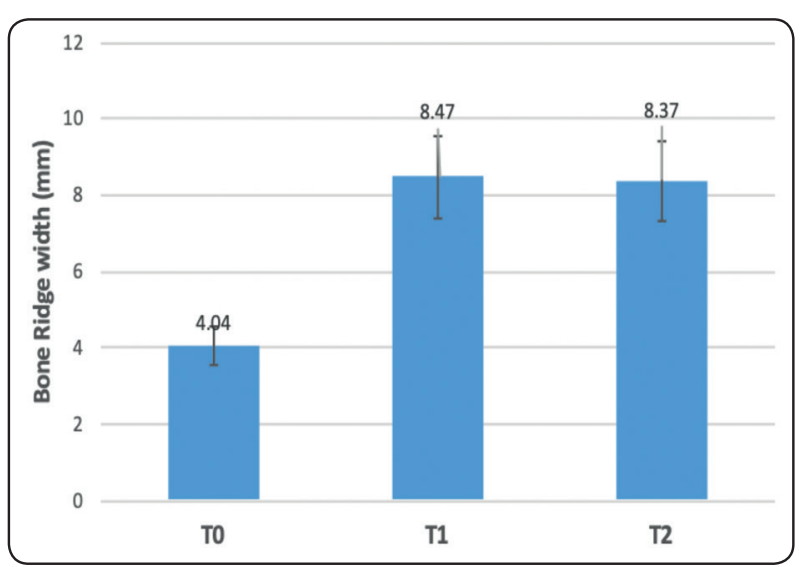

Fig. (5) Changes in bone ridge width within the post-operative follow-up period.

\section{DISCUSSION}

Prosthetic rehabilitation of patients with atrophic ridge is a common problem in oral and maxillofacial surgery. ${ }^{18-20}$ It is a well-known fact that after tooth loss, the alveolar ridge undergoes bone resorption with more reduction of the ridge width buccolingually initially rather than the ridge height. ${ }^{21}$ The degree of bone resorption in the mandible is more extensive than that in the maxilla, moreover, the posterior segments show higher grades of resorption than the anterior segments. ${ }^{22,23}$ Since the deficiency of the residual ridge width can complicate the implant procedures, the goal of this study was to correct narrow posterior mandible facilitating the placement of large diameter implants by an alternative simple low-cost technique.

In the current study, the delayed expansion technique permitted the placement of the conventional dental implants without fracturing the buccal cortical plate of bone during the expansion procedures. This could be achieved by performing the vertical and apical horizontal osteotomies during the first stage of the surgery without expanding the bone, which was postponed to the second stage of surgery to decrease risk of fracture. This was in accordance with many studies which emphasized the formation of flexible immature bone callus at the sites of corticotomy after a staged approach,

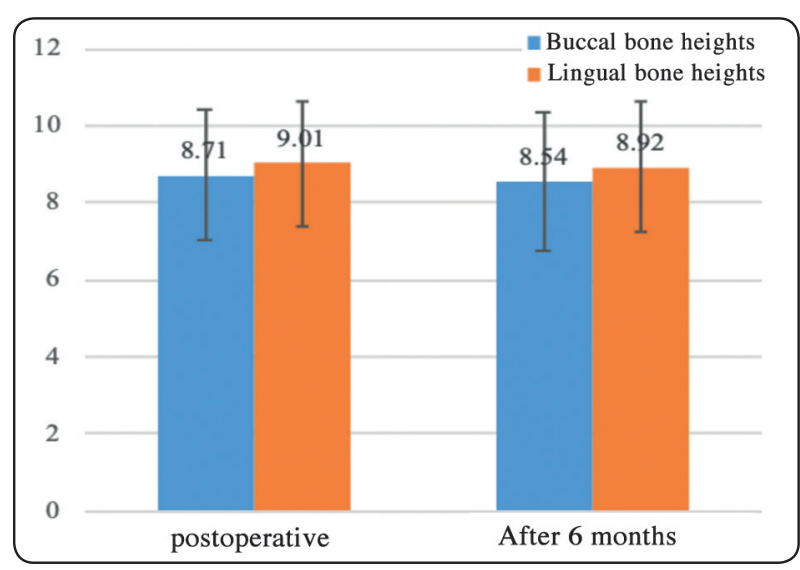

Fig. (6): Changes in the buccal and lingual bone heights within the postoperative follow up period.

permitting the splitting procedure. ${ }^{17,24}$ Preservation of the lingual periosteum in the first stage and the buccal periosteum in the second stage of surgery maintained adequate blood supply to the bone. Since this technique was performed in two stages, the site of the greenstick fracture could be predicted and predetermined. ${ }^{25}$

Piezoelectric device was used to perform corticotomies in this study. Its positive effects on bone viability have been reported by several studies in oral surgery. ${ }^{26,27}$ Consideration of the biological impact of mechanical instruments on the bone structure as well as the cells viability is important in regenerative surgery. ${ }^{28,29}$ Comparable implant success rates were recorded in alveolar ridges split with piezoelectric surgery and in intact ridges. ${ }^{30}$

Two stage split technique was the technique of choice in this study although conventional immediate delayed expansion technique (one stage) appeared to be a predictable and efficient method for horizontal reconstruction of narrow alveolar ridges as shown by many studies. ${ }^{31,32}$ However, one stage technique was recommended to be more suitable for maxilla rather than posterior mandibular region due to the dynamic viscoelasticity of bone. ${ }^{17}$ Accordingly, since the mandibular bone is more dense than the maxilla, its viscoelastic nature decreases, yielding the bone expansion more difficult. ${ }^{33}$ 
The delayed expansion technique used in this study seemed to overcome the reported complications of immediate split in mandible as no cases showed fracture of buccal bone or avascular necrosis, this is similar to Chauhan $\mathrm{H}$ et al study ${ }^{\mathbf{1 7}}$ who compared immediate and delayed expansion techniques. They reported some disadvantages of the immediate split technique like mal-fracture of bone segments, implant instability and unsatisfactory placement of the implant buccolingually while delayed technique averted all of these complications.

In this study, the width of the alveolar ridge significantly increased by $4.22 \pm 0.94 \mathrm{~mm}$ on average, ranging from $2.20-5.90 \mathrm{~mm}$, which is similar to the results obtained by Abu Tair. ${ }^{34}$ who reported $3 \mathrm{~mm}$ average gain in ridge width after staged split of mandibular edentulous areas. This was also in agreement with Anitua et al, ${ }^{35}$ who evaluated the two-stage split crest technique for controlled mandibular expansion and obtained mean crest expansion of $7.10 \mathrm{~mm}$. The author concluded that the staged approach provides 2-3 folds increase in the ridge width. Kheur et al, ${ }^{25}$ obtained similar results with the same technique.

This study showed statistically insignificant decrease in buccal and lingual marginal bone level $(0.403 \pm 0.26 \mathrm{~mm} \& 0.217 \pm 0.20 \mathrm{~mm}$ respectively) Similarly, Sethi and Kaus, ${ }^{36}$ who successfully expanded atrophic ridges to $5-6 \mathrm{~mm}$ wide by two stage technique obtained minimal bone loss at crest after 1 year. This decrease in marginal bone level with two-stage technique can be attributed to the predetermined location of the greenstick fracture and preserving blood perfusion for the buccal cortical plate which in turn reduces the bone resorption. Another study explained that pushing the designed trapezoid bone buccally, vascularization assures the nutrition supply to the bone block, eliminating the risk of necrosis and absorption. ${ }^{37}$ However, the result of this study did not agree with Gonzalez-Garcia et al, ${ }^{38}$ who achieved only $0.5 \mathrm{~mm}$ loss of the alveolar bone with single stage split osteotomy. They believed that the staged ridge splitting technique was unnecessary. However, they confirmed that these findings should not be applied to the mandible, since its bone nature has shown less predictable results.

Many researchers have used different bone substitutes during ridge expansion procedures in order to fill the residual gap between the buccal and lingual plates of bone, or to augment the external alveolar crest contour. Additionally, these regions were covered by different types of membranes. 39-41 This was not in accordance with the current study which involved neither bone substitutes nor membranes. Referring to the original ridge expansion technique, bone substitutes are not expected to be used and the space obtained after ridge expansion is maintained by the implant itself allowing a healing process similar to that occurring in the extraction sockets. In the present study, the protocol of Agabiti et $\mathrm{al}^{42}$ was followed. They performed a two-stage ridge-split at narrow alveolar mandibular bone ridges without using any bone substitutes. An integration of various techniques was proposed by Bruschi and Scipioni ${ }^{43}$ who used split-thickness flaps, bone releasing incisions, and immediate implant installation, precluding any grafts or membranes in the technique which was termed "edentulous ridge expansion".

No implant was lost throughout the period of this study obtaining $100 \%$ implant survival rate. The high implant survival rate obtained in this study with delayed split expansion technique is comparable to lateral ridge augmentation with autogenous bone block graft as reported by Altiparmak $\mathrm{N}$ et al, ${ }^{44}$ who obtained $100 \%$ implant survival rate after 38.3 months following split crest technique compared to $92.9 \%$ after 31.6 months following lateral ridge augmentation with autogenous bone block graft. Similarly, a comparative review of Starch-Jensen and Becktor revealed a high implant stability and high implant survival rate with split crest technique with no significant difference compared to lateral ridge augmentation with autogenous bone block. ${ }^{45}$ 
The delayed expansion technique described herein showed to be a suitable alternative to reconstruct extremely narrow mandibular ridge, without harvesting bone from a second surgical site, decreasing morbidity and post-operative complications, meanwhile it provided a greater capacity for bone expansion rather than other aggressive bone harvesting techniques. Other studies reported favorable results by using onlay bone grafting in addition to growth factors. ${ }^{46,47}$ However invasive surgical procedures were used to obtain the graft, and implant placement was delayed for 3-6 months. After 6 months, $20 \%$ to $50 \%$ of the cases reported lateral onlay bone graft resorption. ${ }^{48}$ Regarding the guided bone regeneration procedures, membrane collapse and exposure with subsequent infection were recorded as the major drawbacks. ${ }^{49}$ Using the two stage split expansion technique without guided bone regeneration overcomes these drawbacks and provides sufficient bone width for successful implant placement with comparable results to other augmentation techniques.

In summary, the use of delayed expansion technique in this study was very efficient for horizontal augmentation of narrow posterior mandibular ridge. Neither bone grafts nor membranes were used. The technique provided an adequate amount of bony base for placement of wider diameter implants with high implant survival rate, offering no complications, less morbidity and cost than other augmentation techniques.

\section{CONCLUSION}

The use of delayed expansion technique without guided bone regeneration is a simple efficient technique for horizontal augmentation of narrow posterior mandibular ridge for implant placement. It offers less incidence of complications, less morbidity and cost than other augmentation techniques. It represents a modification of the conventional technique and is especially interesting for those patients with highly compact bone and initial insufficient bone ridge width for implant placement.

\section{RECOMMENDATION}

More studies with a larger number of cases and longer periods of follow-up are necessary to confirm the results.

\section{ABBREVIATIONS}

- GBR: Guided bone regeneration.

- MSCT: Multi-slice spiral computed tomography.

\section{REFERENCES}

1. Agarwal N, Pai UY, Rodrigues SJ, and Baral S. Ridge splitting for horizontal bone augmentation with Guided Bone Regeneration (GBR) and simultaneous implant placement. JNPS 2020;3(1):37-43.

2. Elian N, Jalbout Z, Ehrlich B, Classi A, Cho SC, AlKahtani F, Froum S, and Tarnow DP. A two-stage full-arch ridge expansion technique: review of the literature and clinical guidelines.Implant Dent.2008;17(1):16-23.

3. Takahashi T., Funaki K., Shintani H., and Haruoka T.. Use of horizontal alveolar distraction osteogenesis for implant placement in a narrow alveolar ridge: a case report. Int $\mathrm{J}$ Oral Maxillofac Implants. 2004; 9(2):291-94.

4. $\mathrm{Li} \mathrm{X}, \mathrm{Xu} \mathrm{P}, \mathrm{Xu} \mathrm{X}$, and Liu S. The application of a delayed expansion technique for horizontal alveolar ridge augmentation in dental implantation. Int J Oral Maxillofac Surg. 2017;46(11):1451-7.

5. Tatum Jr. H. Maxillary and sinus implant reconstructions Dent Clin North Am. 1986; 30:207-29.

6. Shahakbari R, Eshghpour M, Mianbandi V, Pourgonabadi S, Tohidi E, Seyedi SJ, and Samieirad S. The comparison of utilizing piezotome and surgical disc in ridge splitting of atrophic edentulous maxillary ridge. J Maxillofac Oral Surg. 2019; 5:1-6.

7. Suh JJ, Shelemay A, Choi SH, and Chai JK. Alveolar ridge splitting: a new microsaw technique. Int $\mathrm{J}$ Periodontics Restorative Dent.2005:25:165-71

8. Moro A, Gasparini G, Foresta E, Saponaro G, Falchi M, Cardarelli L, De Angelis P, Forcione M, Garagiola U, D'Amato G, and Pelo S. Alveolar ridge split technique using piezosurgery with specially designed tips. BioMed Res. Int. 2017;29

9. Ahmed AO, Hussien MM, and Mahmoud AA. Effect of ultrasonic ridge splitting technique with simultaneous 
implants placement into narrow posterior mandibular alveolar ridge: a clinical and radiographic study. ADJ. 2018;21(5):443-50.

10. Bravi F, Bruschi GB, and Ferrini F. A 10-year multicenter retrospective clinical study of 1715 implants placed with the edentulous ridge expansion technique. Int $\mathrm{J}$ Periodontics Restorative Dent 2007; 27:557-65.

11. Rosalem JM, Engel DP, Bôa MP, Maurity TN, and da Silva Brum I. Oral rehabilitation in mandibula with implants and nano-biomaterial, using the split-crest technique: A case report. J Case Rep Images Surg 2020;6.

12. Papathanasiou I, Georgios V, Baltiras S, and Zouloumis L. Ridge splitting technique for horizontal augmentation and immediate implant placement.BJDM. 2014;18(1):41-7.

13. Basa S, Varol A, and Turker N. Alternative bone expansion technique for immediate placement of implants in the edentulous posterior mandibular ridge: a clinical report. Int J Oral Maxillofac Implants. 2004;19(4):554-558.

14. Piccinini M. Mandibular bone expansion technique in conjunction with root form implants: a case report. J Oral Maxillofac Surg. 2009; 67:1931-36.

15. Chiapasco M, Zaniboni M, and Boisco M. Augmentation procedures for the rehabilitation of deficient edentulous ridges with oral implants. Clin Oral Implants Res 2006; 17:136- 59 .

16. Eduardo Anitua, Leire Begoña, and Gorka Orive. Controlled Ridge Expansion Using a Two-Stage SplitCrest Technique with Ultrasonic Bone Surgery. Implant Dent 2012; 21:163-70.

17. Chauhan H, Lakshmi S, Aurora JK, Potlia I, Komal A, and Purohit N. Comparison between immediate vs. delayed lateral expansion technique to augment narrow alveolar ridges for placement of implants-A pilot study. J Oral Biol Craniofac Res. 2020;10(2):78-82.

18. Felice P, Piattelli A, Iezzi G, Degidi M, and Marchetti C. Reconstruction of an atrophied posterior mandible with an inlay technique and inorganic bovine bone block: a case report. Int J Periodontics Restorative Dent 2010; 30:58391.14.

19. Esposito M, Pellegrino G, Pistilli R, and Felice P. Rehabilitation of posterior atrophic edentulous jaws: prostheses supported by $5 \mathrm{~mm}$ short implants or by longer implants in augmented bone? One-year results from a pilot randomised clinical trial. Eur J Oral Implantol 2011; 4:21-30.
20. Felice P, Piana L, Checchi L, Pistilli R, and Pellegrino $\mathrm{G}$. Vertical ridge augmentation of the atrophic posterior mandible with a 2-stage inlay technique: a case report. Implant Dent 2012; 21:190-5.

21. Reich KM, Huber CD, Lippnig WR, Ulm C, Watzek G., and Tangl S, Atrophy of the residual alveolar ridge following tooth loss in an historical population. Oral Dis. 2011;17(1): 33-44.

22. Knezović-Zlatarić D., A. Čelebić, and B. Lazić. Resorptive changes of maxillary and mandibular bone structures in removable denture wearers. Acta Stomatol Croat. 2002;36(2).

23. Pietrokovski J, Massler M. Alveolar ridge resorption following tooth extraction. J Prosthet Dent. 1967; 17(1): 21-27.

24. Scipioni A, Bruschi GB, and Calesini G. The edentulous ridge expansion technique: a five year study. Int $\mathrm{J}$ Periodontics Restorative Dent. 1994;14(5):451-9.

25. Kheur M, Gokhale S, Sumanth S, and Jambekar S. Staged ridge splitting technique for horizontal expansion in mandible: a case report. J Oral Implantol. 2014;40(4):479-83.

26. Berengo M, Bacci C, Sartori M, Perini A, Della Barbara M, and Valente M. Histomorphometric evaluation of bone grafts harvested by different methods. Minerva Stomatol. 2006;55(4):189-98.

27. Sohn DS, Ahn MR, Lee WH, Yeo DS, and Lim SY. Piezoelectric osteotomy for intraoral harvesting of bone blocks. Int J Periodontics Restorative Dent. 2007; 27(2):127-31.

28. Chiriac G, Herten M, Schwarz F, Rothamel D, and Becker J. Autogenous bone chips: influence of a new piezoelectric device (Piezosurgery ${ }^{\circledR}$ ) on chip morphology, cell viability and differentiation. J Clin Periodontol. 2005;32(9):994-9.

29. Labanca M,Azzola F, Vinci R, and Rodella LF. Piezoelectric surgery: twenty years of use. Br J Oral Maxillofac Surg.. 2008;46(4):265-9.

30. Danza M, Guidi R, and Carinci F. Comparison between implants inserted into piezo split and unsplit alveolar crests. J Oral Maxillofac Surg 2009; 67:2460-65.

31. Hamdan H, Aoun G, Nassar J, and Salame TH. Evaluation of the Split-crest Technique with SimultaneousImplant Placement in Atrophic Edentulous Maxillary and Mandibular Bone: A 5-Year Follow-up Study. J Adv Med Med Res. 2021;12:31-7. 
32. Abou Hamdan H, Salame TH, and Aoun G. Full Mouth Rehabilitation Using Alveolar Ridge Splitting Technique with Immediate Implant Placement in the Maxilla and Delayed Implant Placement in the Mandible: A Case Report with 4 Years Follow-Up. JAMMR. 2021(3):81-9.

33. Misch C.E. Density of bone: effect on treatment plans, surgical approach, healing, and progressive bone loading. Int J Oral Implant. 1990; 6:23-31.

34. Abu Tair JA. Modification of mandibular ridge splitting technique for horizontal augmentation of atrophic ridges. Ann Maxillofac Surg 2014; 4:19-23.

35. Anitua E, Begoña L, and Orive G. Two-stage split-crest technique with ultrasonic bone surgery for controlled ridge expansion: a novel modified technique. Oral Surg Oral Med Oral Pathol Oral Radiol Endod. 2011; 112(6):708-10.

36. Sethi A and Kaus T. Maxillary ridge expansion with simultaneous implant placement: 5-Year results of an ongoing clinical study. Int J Oral Maxillofac Implants 2000; $15: 491$.

37. Scarano A, Piattelli A, Murmura G, Iezzi G, Assenza B and Mancino C. Delayed expansion of the atrophic mandible by ultrasonic sur- gery: a clinical and histologic case series. Int J Oral Maxillofac Implants 2015; 30:144-9.

38. Gonzalez-Garcia R, Monje F and Moreno C. Alveolar split osteotomy for the treatment of the severe narrow ridge maxillary atrophy: a modified technique. Int. J. Oral Maxillofac. Surg. 2011; 40: 57-64.

39. Anitua E and Alkhraisat MH. Is Alveolar Ridge Split a Risk Factor for Implant Survival? J Oral Maxillofac Surg. 2016;74(11):2182-91

40. Kim NH, Bang JH, and Lee DW. Implant placement in severely atrophic mandible using alveolar ridge splitting procedure and small block bone graft: A case report of 4-year follow-up. KAED 2019;28(2):64-73.

41. Ella B., Laurentjoye M., Sedarat C., Coutant JC., Masson E., and Rouas A. Mandibular ridge expansion using a horizontal bone-splitting technique and synthetic bone substitute: an alternative to bone block grafting? Int J Oral Maxillofac Implants. 2014;29(1):135-40.

42. Agabiti I and Botticelli D. Two-Stage Ridge Split at Narrow Alveolar Mandibular Bone Ridges. J Oral Maxillofac Surg. 2017;75(10):2115-e1.

43. Bruschi GB and Scipioni A. Alveolar augmentation: New application for implants. Osseointegration Implants. 1990;2:35-61.

44. Altiparmak N, Akdeniz SS, Bayram B, Gulsever S, and Uckan S. Alveolar Ridge Splitting Versus Autogenous Onlay Bone Grafting: Complications and Implant Survival Rates. Implant Dent. 2017;26(2):284-87.

45. Starch-Jensen T and Becktor JP. Maxillary alveolar ridge expansion with split-crest technique compared with lateral ridge augmentation with autogenous bone block graft: A systematic review. J Oral Maxillofac Res 2019;10(4):e2.

46. De Angelis N, and Scivetti M. Lateral ridge augmentation using an equine flex bone block infused with recombinant human platelet-derived growth factor BB: a clinical and histologic study. Int J Periodontics Restorative Dent 2011; $31: 383-8$

47. Simion M, Rocchietta I, and Dellavia C. Three-dimensional ridge augmentation with xenograft and recombinant human platelet-derived growth factor-BB in humans: report of two cases. Int J Periodontics Restorative Dent 2007; 27(2):109-15

48. Cordaro L, Amade DS, and Cordaro M. Clinical results of alveolar ridge augmentation with mandibular block grafts in partially edentulous patients prior to implant placement. Clin Oral Implants Res 2002; 13:103-11.

49. Chiapasco M, Abati S, Romeo E, and Vogel G. Clinical outcome of autogenous bone blocks or guided bone regeneration with e-PTFE membranes for the reconstruction of narrow edentulous ridges. Clin Oral Implants Res 1999; 10:278-88. 